\title{
ChemComm
}

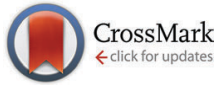

Cite this: Chem. Commun., 2016, 52,4722

Received 19th January 2016 ,

Accepted 26th February 2016

DOI: $10.1039 / c 6 c c 00534 a$

www.rsc.org/chemcomm

\section{Unraveling a two-step oxidation mechanism in electrochemical Cu-MOF synthesis $\dagger$}

\author{
Philipp Schäfer, ${ }^{a}$ Monique A. van der Veen ${ }^{\star b}$ and Katrin F. Domke ${ }^{\star^{a}}$
}

To employ the full potential of electrochemical (ec) synthesis to grow metal-organic frameworks (MOFs) in more complex organizations at the mesoscale, it is vital to understand the underlying crystallization reaction pathway. For the MOF most typically grown electrochemically, CuBTC, we systematically investigated the role of oxygen species in the synthesis.

Metal-organic frameworks (MOFs) attract significant interest as versatile materials for gas separation ${ }^{1}$ and storage, ${ }^{2}$ and more recently as light harvesters for novel energy conversion schemes., Their topology (crystal structure, pore size, pore connectivity) and functionality (chemistry at reactive sites, luminescence/absorption properties of framework, guest donor/acceptor moieties) can, in principle, be tuned to desire by making use of the wealth of metal ion and organic linker combinations the chemist's tool kit provides. While classically, MOFs are synthesized solvothermally at elevated pressure and/or temperature, ${ }^{5,6}$ recently, novel anodic and cathodic ${ }^{7-12}$ electrochemical (ec) fabrication protocols are emerging as electrosynthesis offers milder conditions, greater energy efficiency and energetic control over the MOF growth. ${ }^{7,13,14}$

It has been shown that by applying an appropriate synthesis potential, the size of MOF crystals can be directly controlled in the sub- to $5 \mu \mathrm{m}$ size range, ${ }^{7,8}$ or that different linkers can be built in on demand to fabricate multi-functionality MOFs in situ. ${ }^{10}$ These cases demonstrate the extraordinary possibilities electrosynthesis offers for controlled MOF growth. However, generalizing the ec approach requires a detailed understanding of the underlying reaction mechanisms which have to date only been speculated on. ${ }^{7,15}$ Questions regarding the chemical species involved, the role of the substrate surface and the energetics and

${ }^{a}$ Max Planck Institute for Polymer Research, Molecular Spectroscopy Department, Ackermannweg 10, D 55128 Mainz, Germany. E-mail: domke@mpip-mainz.mpg.de ${ }^{b}$ Delft University of Technology, Faculty of Applied Sciences, Chemical Engineering Department, Section of Catalysis Engineering, Julianalaan 136, NL 2628 BL Delft, Netherlands. E-mail: M.A.vanderVeen@tudelft.nl

$\dagger$ Electronic supplementary information (ESI) available: Materials and methods (Raman, XRD, SEM data); characterization of Samples F. Current transients. See DOI: $10.1039 / \mathrm{c} 6 \mathrm{cc} 00534 \mathrm{a}$ kinetics of the overall reaction pathway of ec MOF formation need to be answered to mature ec synthesis into a readily available tool for rational MOF design.

In this work, we unravel the reaction mechanism of the ec formation of a showcase MOF, CuBTC (HKUST-1; Cu 1,3,5 tricarboxylic acid). Prepared according to the original protocol from 2005, electrosynthesized CuBTC, finds large-scale application e.g. for carbon dioxide/methane ${ }^{16}$ or propylene/propane ${ }^{17}$ gas mixture separation, or in novel sensors and electronic devices. ${ }^{18}$ Despite CuBTC being one of the most extensively studied MOFs, ${ }^{7,19}$ its ec formation mechanism has not yet been unraveled, hindering full exploitation of electrosynthetic MOF design possibilities. It has been postulated that, $\mathrm{Cu}$ is anodically oxidized in one step to $\mathrm{Cu}^{2+}$ followed by linker coordination in solution. ${ }^{7,15}$ Other groups, however, have observed MOF crystals intergrown with the surface that suggest on-surface growth. ${ }^{20}$

To solve the prevailing controversy and open a route for rational MOF topology and functionality design, we set out to identify the chemical species involved in CuBTC electro-synthesis and unravel the reaction mechanism. We systematically varied the experimental conditions such as the $\mathrm{Cu}$ source, the presence of $\mathrm{O}_{2}$ and the applied potential (Table 1), generally following the protocol found in literature: ${ }^{7,21}$ a Cu plate was immersed at open circuit in a mixture of $100 \mathrm{~mL}$ absolute EtOH, $3 \mathrm{~g}$ BTC linker and

Table 1 Experimental conditions, sample overview

\begin{tabular}{lllll}
\hline $\begin{array}{l}\text { Sample } \\
\text { type }\end{array}$ & Cu source & $\mathrm{O}_{2}$ presence & $\begin{array}{l}E^{a} / \text { reaction } \\
\text { time }\end{array}$ & $\begin{array}{l}\text { CuBTC } \\
\text { formation }\end{array}$ \\
\hline $\mathrm{A}$ & $\begin{array}{l}\text { Cu with natural } \\
\text { oxide layer }\end{array}$ & Yes & $1 \mathrm{~V} / 20 \mathrm{~min}$ & Yes \\
$\mathrm{B}$ & $\begin{array}{l}\mathrm{Cu} \text { oxide free } \\
\text { Cu with artificial } \\
\text { oxide layer }\end{array}$ & $\mathrm{No}$ & $1 \mathrm{~V} / 20 \mathrm{~min}$ & $\mathrm{No}$ \\
$\mathrm{C}$ & $\mathrm{No}$ & $1 \mathrm{~V} / 20 \mathrm{~min}$ & Yes \\
$\mathrm{D}$ & $\mathrm{Cu}_{2} \mathrm{O}$ & Yes & No/16 hours & Yes \\
$\mathrm{E}$ & $\mathrm{Cu}_{2} \mathrm{O}$ & Low amount & No/16 hours & $\begin{array}{l}\text { Yes } \\
\text { (truncated) }\end{array}$ \\
$\mathrm{F}^{b}$ & $\mathrm{CuO}$ & Yes & No/16 hours & No
\end{tabular}

${ }^{a}$ Potentials reported $v s . \mathrm{Ag} / \mathrm{AgCl} / 3 \mathrm{M} \mathrm{KCl} .{ }^{b} \mathrm{SEM} /$ Raman characterization in ESI. 
$1 \mathrm{~g}$ methyl tributyl ammonium methyl sulfate electrolyte. After electrode immersion, a potential of $E=1 \mathrm{~V} v s$. $\mathrm{Ag} / \mathrm{Ag} \mathrm{Cl}$ was applied for $20 \mathrm{~min}$. To prevent $\mathrm{Cu}_{2} \mathrm{O}$ formation on the $\mathrm{Cu}$ electrode from ambient aerobic corrosion in $\mathrm{O}_{2}$-free experiments, EtOH was degassed with $\mathrm{Ar}$ for $20 \mathrm{~min}$ prior to $\mathrm{Cu}$ immersion, and the ec cell was constantly kept under Ar. To remove the natural oxide layer (comprised mainly of $\mathrm{Cu}_{2} \mathrm{O}$ and a small amount of $\mathrm{CuO}$ and $\mathrm{Cu}(\mathrm{OH})_{2}{ }^{22}$ ), the $\mathrm{Cu}$ electrode was etched with $25 \% \mathrm{HNO}_{3}$ and $25 \%$ $\mathrm{HCl}^{23}$ before transfer to the synthesis cell.

The resulting topography and chemical composition of each sample type was characterized to determine whether CuBTC grows under the respective conditions. CuBTC is known to form octahedral crystals that can be seen with scanning electron microscopy (SEM). ${ }^{24}$ Raman in-plane ring bending vibrations at 743 and $825 \mathrm{~cm}^{-1}$ of the BTC moiety in CuBTC confirm the presence of CuBTC (Fig. S2 and Table S1, ESI $\dagger$ ). ${ }^{25}$ X-ray diffraction (XRD) was used for CuBTC identification where a sufficient amount of MOF crystals was obtained (see ESI, $\dagger$ for experimental details).

Fig. 1 shows the SEM and Raman results for the different sample types under investigation. Samples A were fabricated under synthesis conditions similar to the ec synthesis protocols found in literature, ${ }^{7,21}$ i.e. starting from a $\mathrm{Cu}$-electrode with a natural oxide layer and taking no precautions to avoid the presence of $\mathrm{O}_{2}$. As expected, octahedral crystals of CuBTC of $<1 \mu \mathrm{m}$ to $5 \mu \mathrm{m}$ in diameter form (Fig. 1A). Electrode coverage is incomplete at $\sim 20$ particles per $100 \mu \mathrm{m}^{2}$, likely due to the low potential of $1 \mathrm{~V}$. An increased synthesis time should improve surface coverage. The corresponding Raman spectrum in the inset of Fig. 1A displays the characteristic bending vibrations of CuBTC at 743 and $825 \mathrm{~cm}^{-1}$, and XRD diffractograms confirm the successful synthesis of CuBTC (Fig. S1A, ESI $\dagger$ ). Note that the Raman spectrum also shows a significant contribution of $\mathrm{Cu}_{2} \mathrm{O}$ (see Fig. S3A, ESI, $\dagger$ broad peaks at 525 and $626 \mathrm{~cm}^{-1}$ ).

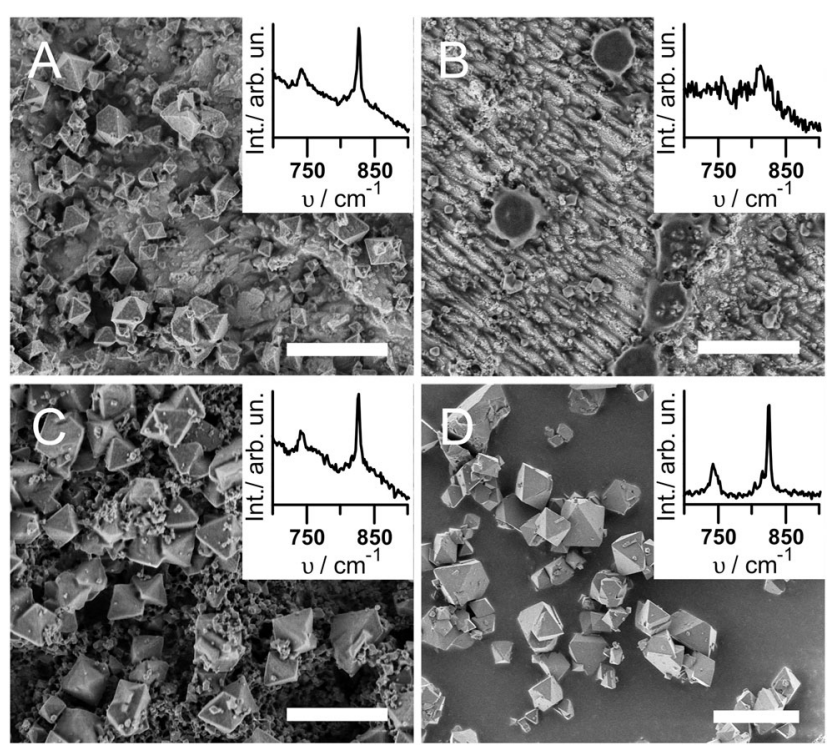

Fig. 1 SEM micrographs and Raman spectra of Samples A to D. Scale bar: $10 \mu \mathrm{m}$.
Samples B were produced under oxide- and $\mathrm{O}_{2}$-free conditions, thus void of all components unnecessary for the $\mathrm{Cu}^{2+}$ dissolutioncoordination mechanism proposed in literature. The SEM image (Fig. 1B) shows parallel Cu tracks due to the acidic etching of the surface. With exception of only about 1 particle per $100 \mu \mathrm{m}^{2}$ of ca. 0.5 to $1 \mu \mathrm{m}$ diameter, no CuBTC crystals are visible. The CuBTC response in the Raman spectra can hardly be distinguished from the noise (Fig. 1B inset), and no XRD signal of CuBTC was obtained (Fig. S1B, ESI $\dagger$ ).

To find the smallest set of components required to enable CuBTC synthesis, we electrochemically oxidized the surface of the $\mathrm{Cu}$ plate on purpose by immersing it in the electrolyte solution and applying a potential of $1 \mathrm{~V} v s$. $\mathrm{Ag} / \mathrm{AgCl}$ for $25 \mathrm{~min}$ prior to $\mathrm{O}_{2}$-free MOF synthesis (Samples C). SEM, Raman and XRD confirm the successful synthesis of CuBTC (Fig. 1C and Fig. S1C, ESI $\dagger$ ); the Raman spectrum shows a significant $\mathrm{Cu}_{2} \mathrm{O}$ contribution (Fig. S3C, ESI $\dagger$ ). Samples $\mathrm{C}$ are covered with a mixture of about 5 crystals per $100 \mu \mathrm{m}^{2}$ of octahedral crystals of 3 to $5 \mu \mathrm{m}$ diameter and ca. 50 particles per $100 \mu \mathrm{m}^{2}$ in the sub- $\mu \mathrm{m}$ diameter range. At some spots, the smaller crystals cover the larger particles.

From experiments A to $\mathrm{C}$, we learn that oxygen plays an important role in ec CuBTC synthesis as CuBTC crystals do not grow under $\mathrm{O}_{2}$-oxygen free conditions and $\mathrm{Cu}_{2} \mathrm{O}$ is always present on the electrodes. To further investigate the role of oxygen, we used pure oxides as precursors for CuBTC growth. For Samples D, we immersed $\mathrm{Cu}_{2} \mathrm{O}$ powder in an ethanolic solution of 0.15 M BTC without any other additions for $14 \mathrm{hrs}$ under ambient conditions. No potential was applied. A blue powder was isolated by centrifugation and characterized. The SEM micrograph in Fig. 1D shows octahedral crystals of 1 to $5 \mu \mathrm{m}$ diameter that are intergrown into larger agglomerates of 10 to $15 \mu \mathrm{m}$ length. Raman spectra (Fig. 1D inset) and XRD (Fig. S1D, ESI $\dagger$ ) confirm CuBTC synthesis. Interestingly, an analogous experiment with $\mathrm{CuO}$ powder as starting material did not produce any CuBTC (Samples F, ESI $\dagger$ ).

To identify the necessary oxidation agent for the oxidation of $\mathrm{Cu}(\mathrm{I})$ to $\mathrm{Cu}(\mathrm{II})$ in absence of an applied potential, Samples $\mathrm{E}$ were synthesized like Samples $\mathrm{D}$, but in an $\mathrm{O}_{2}$-deficient environment. The solution was degassed for $15 \mathrm{~min}$, but during transfer into a glove box, some $\mathrm{O}_{2}$ could re-dissolve. The SEM micrographs show about $10 \%$ of the $\mathrm{Cu}_{2} \mathrm{O}$ surface covered with octahedral crystals of diameters between 0.3 and $0.7 \mu \mathrm{m}$,
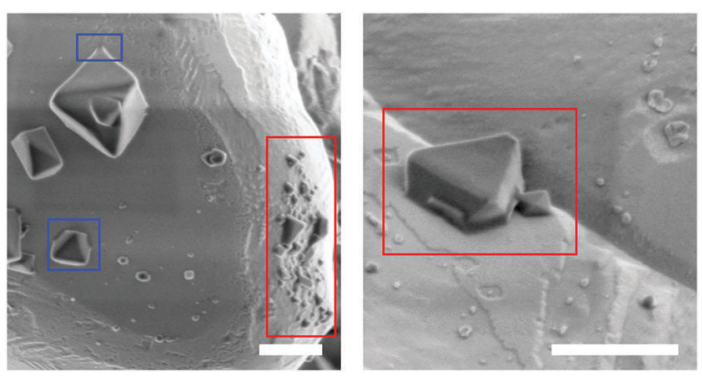

Fig. 2 SEM of Samples E. Red: truncated crystals; blue: intergrowth with surface. Scale bar: $500 \mathrm{~nm}$. 
and partly with what seem to be incomplete CuBTC crystals with diameters of 100 to $200 \mathrm{~nm}$ (Fig. 2, red). This is the only Sample for which we observe incomplete CuBTC octahedrons. It is unlikely that these crystals deposited onto the $\mathrm{Cu}_{2} \mathrm{O}$ substrate during centrifugation; rather they must have grown at the surface, and their growth was halted prematurely due to lack of $\mathrm{O}_{2}$. Similarly, also the few octahedral crystals (Fig. 2, blue) are visibly attached to the $\mathrm{Cu}_{2} \mathrm{O}$ substrate. From these results, we conclude that $\mathrm{O}_{2}$ is the necessary oxidant for the oxidation of $\mathrm{Cu}_{2} \mathrm{O}$ to CuBTC without ec potential. Furthermore, the visible connection between the $\mathrm{CuBTC}$ and the $\mathrm{Cu}_{2} \mathrm{O}$ indicates that CuBTC nucleation likely takes place directly at the $\mathrm{Cu}_{2} \mathrm{O}$ solid/liquid interface. Summing up, the first step to ec CuBTC formation is the oxidation of $\mathrm{Cu}$ to $\mathrm{Cu}^{1+}$ achieved either by ec oxidation of the $\mathrm{Cu}$ anode or by providing $\mathrm{O}_{2}$ and/or $\mathrm{H}_{2} \mathrm{O}$ $\left(\mathrm{H}_{2} \mathrm{O}\right.$ enables CuBTC synthesis even under inert conditions. $\left.{ }^{20}\right)$ as reactant. $\mathrm{Cu}_{2} \mathrm{O}$ is the predominant oxidation product of $\mathrm{Cu}$ in ethanol. ${ }^{26}$ Note that also $\mathrm{Cu}(\mathrm{OH})_{2}$ readily converts into CuBTC in presence of the linker. ${ }^{27}$ While $\mathrm{Cu}(\mathrm{OH})_{2}$ as an intermittent, short-lived reaction intermediate cannot be excluded, our spectroscopic data does not indicate stable $\mathrm{Cu}(\mathrm{OH})_{2}$ formation (i.e. no Raman band at $460 \mathrm{~cm}^{-1}$, Fig. S2b, ESI $\dagger$ ). Furthermore, CuBTC forms directly from $\mathrm{Cu}^{1+}{ }_{2} \mathrm{O}$ powder while $\mathrm{Cu}^{2+} \mathrm{O}$ does not convert to $\mathrm{CuBTC}$ under the given experimental conditions.

As known from literature, $\mathrm{Cu}_{2} \mathrm{O}$ can be produced from $\mathrm{Cu}$ by the following oxidation reactions with $\mathrm{H}_{2} \mathrm{O}$ or $\mathrm{O}_{2}:{ }^{22,28}$

$$
\begin{gathered}
2 \mathrm{Cu}+\mathrm{H}_{2} \mathrm{O} \leftrightarrow \mathrm{Cu}_{2} \mathrm{O}+2 \mathrm{H}^{+}+2 \mathrm{e}^{-} \\
4 \mathrm{Cu}+\mathrm{O}_{2} \leftrightarrow 2 \mathrm{Cu}_{2} \mathrm{O}
\end{gathered}
$$

A positive applied potential facilitates the net release of electrons in reaction (1). Excess electrons are transferred to the counter electrode where a not-further specified counter reaction takes place. Reaction (2) represents the aerobic oxidation of $\mathrm{Cu}$ that takes place in the presence of $\mathrm{O}_{2}$. In Samples B, both (1) and (2) were blocked by using dry EtOH and by degassing the electrolyte with Ar. Since all surface oxides were removed by acidic etching, no $\mathrm{Cu}_{2} \mathrm{O}$ - and thus no CuBTC - could be formed.

Instead of using $\mathrm{O}_{2}$ or $\mathrm{H}_{2} \mathrm{O}$ as oxidant, $\mathrm{Cu}$ can be electrochemically oxidized. In absence of $\mathrm{O}_{2}$ and $\mathrm{H}_{2} \mathrm{O}$, the amount of available $\mathrm{Cu}_{2}^{+1} \mathrm{O}$ is expected to limit the CuBTC yield. Indeed, for Samples C, we did not observe continuous detachment of large MOF crystals from the electrode into the solution phase, indicating that $\mathrm{CuBTC}$ growth stopped after all provided $\mathrm{Cu}_{2} \mathrm{O}$ had been consumed.

For the second oxidation step of $\mathrm{Cu}^{1+}{ }_{2} \mathrm{O}$ to $\mathrm{Cu}^{2+}$ BTC, we propose the following ec half reaction:

$$
3 \mathrm{Cu}_{2} \mathrm{O}+4 \mathrm{H}_{3} \mathrm{BTC} \leftrightarrow 2 \mathrm{Cu}_{3} \mathrm{BTC}_{2}+3 \mathrm{H}_{2} \mathrm{O}+6 \mathrm{e}^{-}+6 \mathrm{H}^{+}
$$

$\mathrm{H}_{2} \mathrm{O}$ is a likely product that can be produced from the oxygen released from $\mathrm{Cu}_{2} \mathrm{O}$ and the protons released from BTC. In the ec synthesis, this oxidation half-reaction takes place at the $\mathrm{Cu}$ anode. (A corresponding, not further specified reduction reaction takes place at the counter electrode.) With the production of $\mathrm{H}_{2} \mathrm{O}$, the reaction should be self-sustaining after a certain threshold $\mathrm{H}_{2} \mathrm{O}$ concentration is reached. For aerobic $\mathrm{Cu}_{2} \mathrm{O}$ oxidation (Samples D), CuBTC growth occurs at the $\mathrm{Cu}_{2} \mathrm{O}$ / solution interface. CuBTC synthesis from $\mathrm{Cu}_{2} \mathrm{O}$ without applied potential is only possible in the presence of $\mathrm{O}_{2}$, as shown by the greatly reduced amount of CuBTC in Samples E. Likely, $\mathrm{O}_{2}$ is reduced to $\mathrm{H}_{2} \mathrm{O}$ in a counter reaction

$$
\mathrm{O}_{2}+4 \mathrm{H}^{+}+4 \mathrm{e}^{-} \leftrightarrow 2 \mathrm{H}_{2} \mathrm{O}
$$

Eqn (3) as the key step in ec CuBTC synthesis as derived from our results is fully consistent with synthesis facts reported in literature: Van Assche et al. showed that CuBTC cannot be produced electrochemically in electrolytes that contain more than $50 \% \mathrm{H}_{2} \mathrm{O}^{20}$ The suppression of the reaction by $\mathrm{H}_{2} \mathrm{O}$ is consistent with $\mathrm{H}_{2} \mathrm{O}$ formation on the product side of (3), leading to an increase of the oxidation potential of the reaction while increasing the propensity for the formation of $\mathrm{H}_{2} \mathrm{O}$-containing catena-triaqua- $\mu$-CuBTC. ${ }^{20}$

Direct oxidation of solid $\mathrm{Cu}_{2} \mathrm{O}$ to $\mathrm{CuBTC}$ at the ec solid/ liquid interface to start crystal nucleation likely explains the tight attachment of CuBTC crystals to the electrode as previously observed $^{7}$ as well as the incomplete CuBTC crystals visibly bound to $\mathrm{Cu}_{2} \mathrm{O}$ that we observe under oxygen-limited conditions; however, a dissolution process with $\mathrm{Cu}_{2} \mathrm{O}$ as intermittent cannot be completely excluded. It remains unclear whether further crystal growth happens at the $\mathrm{Cu}_{2} \mathrm{O}-\mathrm{CuBTC}$-electrolyte interface or continues through a solution-based process with $\mathrm{Cu}^{2+}$ ions attaching to the outer facets of the growing crystal. Campagnol et al. show that electrosynthesized $\mathrm{Cu}$ isonicotinate grows at the MOF-electrolyte interface. ${ }^{29}$ The significant amount of water $(50 \%)^{30}$ that makes $\mathrm{Cu}^{2+}$ ions more soluble in the form of $\left[\mathrm{Cu}\left(\mathrm{H}_{2} \mathrm{O}\right)_{6}\right]^{2+}$ could explain a solution-based process. The lack of $\mathrm{H}_{2} \mathrm{O}$ in our system, however, makes a direct comparison difficult.

Let us summarize the reaction mechanism for the ec oxidation of $\mathrm{Cu}^{0}$ to CuBTC: in presence of $\mathrm{O}_{2}$ and/or $\mathrm{H}_{2} \mathrm{O}, \mathrm{Cu}$ is oxidized in a one-electron step to $\mathrm{Cu}_{2} \mathrm{O}$. A second oxidation step from $\mathrm{Cu}^{1+}$ to $\mathrm{Cu}^{2+}$ in the presence of BTC directly converts $\mathrm{Cu}_{2} \mathrm{O}$ to CuBTC. Involvement of an intermediate $\mathrm{Cu}(\mathrm{I})$ reaction step has not been proposed so far and opens up new pathways to increase control of the synthesis.

Our newly gained knowledge that CuBTC crystallization proceeds through $\mathrm{Cu}_{2} \mathrm{O}$ formation allows us to suggest a novel method to fabricate patterned MOF devices (Fig. 3A). As a proof of principle, we prepared a $\mathrm{Cu}$ substrate with both $\mathrm{Cu}$ and $\mathrm{Cu}_{2} \mathrm{O}$ present by ec oxidizing the surface in the presence of $\mathrm{NaOH} .{ }^{31}$ Then, we selectively removed $\mathrm{Cu}_{2} \mathrm{O}$ in a spot of $\sim 1 \mathrm{~cm}$ diameter in the centre of the sample by pipetting a drop of $10 \% \mathrm{HCl}$. After removal of that drop and subsequent rinsing with $\mathrm{EtOH}$, the $\mathrm{Cu}$ plate was covered with $\mathrm{Cu}_{2} \mathrm{O}$ except for the acid-etched blank $\mathrm{Cu}$ area. Under synthesis conditions $\mathrm{B}\left(\mathrm{O}_{2}\right.$ exclusion, $\left.1 \mathrm{~V}\right)$, CuBTC was grown solely on the oxide-covered part of the sample as discernible in the white-light image (Fig. 3B). The left part of the image where surface oxides were removed by acidic etching shows the pristine $\mathrm{Cu}$ surface. To the right of the image, outside the area of the acid droplet, CuBTC has visibly grown and is spectroscopically detectable. Raman band integration 


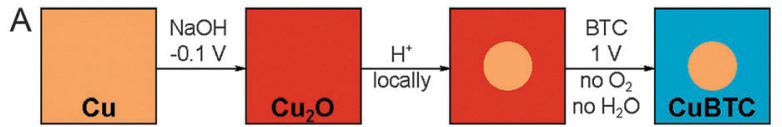

B

of the 800 to $850 \mathrm{~cm}^{-1}$ region provides the relative amounts of CuBTC at different sample positions (Fig. 3C; error bars are standard errors of the mean of three measurements taken at roughly the top, middle and bottom of the white-light image). This facile oxide-based pre-patterning approach can serve as starting point to develop improved synthesis protocols for CuBTC patterning. Current patterning approaches require the use of $\mathrm{Cu}$ electrodes in the desired shape (i.e. printed circuit boards ${ }^{8}$ or $\mathrm{Cu}_{\text {meshes }}{ }^{20}$ ). Our approach offers the possibility to subsequently activate parts of a $\mathrm{Cu}$ substrate. It is easy to imagine how established ways to deposit $\mathrm{Cu}_{2} \mathrm{O}$ as nanoparticles or films ${ }^{32,33}$ or to selectively remove Cu oxide, as shown here, can be converted into a versatile basis for the fabrication of arbitrarily patterned surfaces on $\mathrm{nm}$ to $\mathrm{mm}$ length scales to create devices covered with MOF of controlled sizes at predetermined spots.

To conclude, we unravelled CuBTC electrosynthesis to proceed in a two-step oxidation mechanism at the electrode surface: $\mathrm{Cu}$ is first oxidized to $\mathrm{Cu}^{1+}{ }_{2} \mathrm{O}$ in the presence of $\mathrm{H}_{2} \mathrm{O}$ or $\mathrm{O}_{2} \cdot \mathrm{Cu}_{2} \mathrm{O}$ is further oxidized to $\mathrm{Cu}^{2+} \mathrm{BTC}$ in presence of the linker at the cuprite-electrolyte interface. The MOF octahedrons nucleate directly at the electrode surface and not in solution, rendering the ec mechanism different from the one of solvothermal syntheses with metal salts. ${ }^{34,35}$ We demonstrate how the gained knowledge can be used for a novel quick and versatile approach to produce patterned CuBTC devices.

We thank G. Glasser for SEM measurements, M. Steiert and B. Norder for XRD measurements and the Max Planck Graduate Center and the Studienstiftung des deutschen Volkes for funding. KFD acknowledges generous support through the Emmy Noether Program of the DFG (\#DO1691/1-1).

\section{Notes and references}

1 J. Teufel, H. Oh, M. Hirscher, M. Wahiduzzaman, L. Zhechkov, A. Kuc, T. Heine, D. Denysenko and D. Volkmer, Adv. Mater., 2013, 25, 635-639.

2 A. U. Czaja, N. Trukhan and U. Müller, Chem. Soc. Rev., 2009, 38, 1284-1293.

3 X. Zhang, W. Wang, Z. Hu, G. Wang and K. Uvdal, Coord. Chem. Rev., 2015, 284, 206-235.

4 M. A. Nasalevich, M. van der Veen, F. Kapteijn and J. Gascon, CrystEngComm, 2014, 16, 4919.

5 M. G. Goesten, F. Kapteijn and J. Gascon, CrystEngComm, 2013, 15, 9249.

6 Y.-R. Lee, J. Kim and W.-S. Ahn, Korean J. Chem. Eng., 2013, 30, $1667-1680$

7 A. Martinez Joaristi, J. Juan-Alcañiz, P. Serra-Crespo, F. Kapteijn and J. Gascon, Cryst. Growth Des., 2012, 12, 3489-3498.

8 R. Ameloot, L. Stappers, J. Fransaer, L. Alaerts, B. F. Sels and D. E. De Vos, Chem. Mater., 2009, 21, 2580-2582.

9 I. Hod, W. Bury, D. M. Karlin, P. Deria, C. W. Kung, M. J. Katz, M. So, B. Klahr, D. N. Jin, Y. W. Chung, T. W. Odom, O. K. Farha and J. T. Hupp, Adv. Mater., 2014, 26, 6295-6300.

10 M. Li and M. Dincă, Chem. Sci., 2014, 5, 107.

11 M. Li and M. Dincă, Chem. Mater., 2015, 27, 3203-3206.

12 I. Stassen, M. Styles, T. R. C. Van Assche, N. Campagnol, J. Fransaer, J. F. M. Denayer, J. C. Tan, P. Falcaro, D. E. De Vos and R. Ameloot, Chem. Mater., 2015, 27, 1801-1807.

13 N. Campagnol, T. R. C. Van Assche, T. Boudewijns, J. F. M. Denayer, K. Binnemans, D. E. De Vos and J. Fransaer, J. Mater. Chem. A, 2013, $1,5827$.

14 M. Li and M. Dincă, J. Am. Chem. Soc., 2011, 133, 12926-12929.

15 H. Al-Kutubi, J. Gascon, E. J. R. Sudhölter and L. Rassaei, ChemElectroChem, 2015, 2, 462-474.

16 T. Asadi, M. R. Ehsani, A. M. Ribeiro, J. M. Loureiro and A. E. Rodrigues, Chem. Eng. Technol., 2013, 36, 1231-1239.

17 J.-W. Yoon, I.-T. Jang, K.-Y. Lee, Y.-K. Hwang and J.-S. Chang, Bull. Korean Chem. Soc., 2010, 31, 220-223.

18 J. Gascon and F. Kapteijn, Angew. Chem., Int. Ed., 2010, 49, 1530-1532.

19 B. Panella, M. Hirscher, H. Pütter and U. Müller, Adv. Funct. Mater., 2006, 16, 520-524.

20 T. R. C. Van Assche, G. Desmet, R. Ameloot, D. E. De Vos, H. Terryn and J. F. M. Denayer, Microporous Mesoporous Mater., 2012, 158, 209-213.

21 T. R. C. Van Assche and J. F. M. Denayer, Chem. Eng. Sci., 2013, 95, 65-72.

22 I. Platzman, R. Brener, H. Haick and R. Tannenbaum, J. Phys. Chem. $C, 2008,112,1101-1108$.

23 L. C. Hall, C. P. Major, J. J. Steppan, J. A. Roth and B. K. Vaughen, J. Electrochem. Soc., 1987, 134, 1902.

24 Q. Min Wang, D. Shen, M. Bülow, M. Ling Lau, S. Deng, F. R. Fitch, N. O. Lemcoff and J. Semanscin, Microporous Mesoporous Mater., 2002, 55, 217-230.

25 C. Prestipino, L. Regli, J. G. Vitillo, F. Bonino, a. Damin, C. Lamberti, a. Zecchina, P. L. Solari, K. O. Kongshaug and S. Bordiga, Chem. Mater., 2006, 18, 1337-1346.

26 B. Stypuła, J. Banaś, M. Starowicz, H. Krawiec, A. Bernasik and A. Janas, J. Appl. Electrochem., 2006, 36, 1407-1414.

27 G. Majano and J. Perez-Ramirez, Adv. Mater., 2013, 25, 1052-1057.

28 H. Y. H. Chan, C. G. Takoudis and M. J. Weaver, J. Phys. Chem. B, 1999, 103, 357-365.

29 N. Campagnol, T. R. C. Van Assche, L. Stappers, J. F. M. Denayer, K. Binnemans, D. E. De Vos and J. Fransaer, ECS Trans., 2014, 61, 25-40.

30 B. Van de Voorde, R. Ameloot, I. Stassen, M. Everaert, D. E. De Vos and J.-C. Tan, J. Mater. Chem. C, 2013, 1, 7716.

31 J. C. Hamilton, J. C. Farmer and R. J. Anderson, J. Electrochem. Soc., 1986, 133, 739.

32 P. E. de Jongh, D. Vanmaekelbergh, J. J. Kelly and P. E. D. Jongh, Chem. Mater., 1999, 11, 3512-3517.

33 D. P. Singh, N. R. Neti, A. S. K. Sinha and O. N. Srivastava, J. Phys. Chem. C, 2007, 111, 1638-1645.

34 V. Stavila, J. Volponi, A. M. Katzenmeyer, M. C. Dixon and M. D. Allendorf, Chem. Sci., 2012, 3, 1531.

35 O. Shekhah, H. Wang, D. Zacher, R. A. Fischer and C. Wöll, Angew. Chem., Int. Ed., 2009, 48, 5038-5041. 